University of Nebraska - Lincoln

DigitalCommons@University of Nebraska - Lincoln

2012

\title{
One-step fabrication of L10 FePt nanocubes and rods by cluster beam deposition
}

\author{
W Li \\ University of Delaware, Newark \\ O Akdogan \\ University of Delaware, Newark \\ George C. Hadjipanayis \\ University of Delaware, hadji@udel.edu \\ Ralph Skomski \\ University of Nebraska-Lincoln, rskomski2@unl.edu \\ David J. Sellmyer \\ University of Nebraska-Lincoln, dsellmyer@unl.edu
}

Follow this and additional works at: https://digitalcommons.unl.edu/physicssellmyer

Part of the Physics Commons

Li, W; Akdogan, O; Hadjipanayis, George C.; Skomski, Ralph; and Sellmyer, David J., "One-step fabrication of L10 FePt nanocubes and rods by cluster beam deposition" (2012). David Sellmyer Publications. 233. https://digitalcommons.unl.edu/physicssellmyer/233

This Article is brought to you for free and open access by the Research Papers in Physics and Astronomy at DigitalCommons@University of Nebraska - Lincoln. It has been accepted for inclusion in David Sellmyer Publications by an authorized administrator of DigitalCommons@University of Nebraska - Lincoln. 


\title{
One-step fabrication of $\mathrm{L} 1_{0} \mathrm{FePt}$ nanocubes and rods by cluster beam deposition
}

\author{
O. Akdogan, ${ }^{1, a)}$ W. Li, ${ }^{1}$ G. C. Hadjipanayis, ${ }^{1}$ R. Skomski, ${ }^{2}$ and D. J. Sellmyer ${ }^{2}$ \\ ${ }^{1}$ Department of Physics and Astronomy, University of Delaware, Newark, Delaware 19711, USA \\ ${ }^{2}$ Department of Physics and Astronomy, University of Nebraska, Lincoln, Nebraska 68588, USA
}

(Presented 31 October 2011; received 23 September 2011; accepted 3 December 2011; published online 12 March 2012)

\begin{abstract}
In this work, single crystal $\mathrm{L}_{0} \mathrm{FePt}$ nanocubes have been successfully produced by a cluster beam deposition technique without the need of post annealing. Particles have been deposited by dc magnetron sputtering using high Ar pressures on both single crystal Si substrates and Au grids for the measurement of magnetic and structural properties, respectively. The nanocubes have a uniform size distribution with an average size of $5 \mathrm{~nm}$. At 1 Torr, the particles have the $\mathrm{L1}_{0}$ structure with an order parameter of 0.5 and a RT coercivity of $2 \mathrm{kOe}$ with high switching fields observed in the hysteresis loop. Further annealing increased the particle size to $20 \mathrm{~nm}$ and the RT coercivity to $10.2 \mathrm{kOe}$ with perfect chemical ordering. In addition to these nanocubes, micron size rods with the $\mathrm{L} 1_{0}$ structure have been observed near the cluster gun. SEM analysis showed that these rods consist of nanoparticles with $20 \mathrm{~nm}$ average size. Surfactant assisted high-energy ball milling has been used to separate the nanoparticles from the rods. After one hour of milling, these $20 \mathrm{~nm}$ particles showed a room temperature coercivity of $9 \mathrm{kOe}$ with an order parameter of 0.85 . These FePt nanocubes have a potential for use in the development of future high-density magnetic recording media because of their high coercivity, good shape and very narrow size distribution. (C) 2012 American Institute of Physics. [doi:10.1063/1.3679085]
\end{abstract}

\section{INTRODUCTION}

In the last decade, there has been an increasing emphasis on exploiting the size-dependent behavior of magnetic nanostructures. Such studies are important for tailoring the particle properties for the specific application. ${ }^{1,2}$ Magnetic nanoparticles are currently being used in many applications; magnetically soft nanoparticles currently in use for cancer detection as a contrast enhancer (MRI) and for cancer treatment as a targeted drug carrier. ${ }^{3}$ On the other hand, magnetically hard nanoparticles are currently in use for magnetic filters, magnetic sensors, development of high performance magnets as building blocks for the bottom-up approach and most importantly for the development of ultra high-density magnetic recording media. ${ }^{4,5}$

Fabrication of well-separated, single crystal nanoparticles with moderate coercivity plays a key role in the development of high density recording media. Possible candidates for this application are the Sm-Co, Nd-Fe-B or ( Fe, Co)-( $\mathrm{Pt}$, $\mathrm{Pd}$ ) alloy nanoparticles due to their high magnetic anisotropy that overcomes the superparamagnetic limit. ${ }^{5}$ Production and final use of Rare Earth based nanoparticles are very troublesome due to the high reactivity of these materials. In contrary, FePt nanoparticles are extremely resistant to oxidation.

FePt nanoparticles become magnetically hard when they are formed in the face centered tetragonal $\left(\mathrm{FCT}, \mathrm{L}_{0}\right)$ structure. ${ }^{6,7}$ As-made nanoparticles are usually in the face centered cubic (FCC, A1) structure and post annealing is necessary for the phase transition to FCT, which results in uncontrolled agglomeration of nanoparticles. Production of FCT FePt nanoparticles without any post annealing is of a key importance. Most widely used methods to produce as-made FCT phase FePt nanoparticles

\footnotetext{
a) Author to whom correspondence should be addressed. Fax: 1-302-8311637. Electronic mail: oakdogan@udel.edu.
}

include high temperature chemical synthesis ${ }^{8}$ and cluster beam deposition. ${ }^{9,10}$ The latter technique with the introduction of inflight annealing has been used by several groups. ${ }^{9,10}$

Though the method produces the needed nanoparticles, expensive and complicated in-flight annealing ovens have to be constructed. Also, the particle shape cannot be controlled and the ordering is not complete. Qui et al ${ }^{11-13}$ introduced a much simpler and cost effective method to produce FCT FePt nanoparticles. This method uses a Fe pole piece on the top of the target to condense the nanoparticle formation near the cluster gun by extending the field lines around the target. Therefore, particles spend more time near the high current applied target and become $\mathrm{L} 1_{0}$ ordered.

In this work, we used this technique with very high target power $(300 \mathrm{~W})$ to produce shape controlled (nanocubes), well separated, single crystalline nanoparticles with a narrow size distribution. In addition to the nanoparticles, micron size rods consisting of nanoparticles have been produced near the cluster gun.

\section{EXPERIMENT}

Schematic illustration and detailed description of the cluster-beam deposition system can be found elsewhere. ${ }^{14}$ The base pressure in the sputtering chamber was $2 \times 10^{-7}$ Torr and high purity $\operatorname{Ar}(99.9999 \%)$ was used for the deposition with a pressure of $5 \mathrm{mTorr}$ inside the main chamber and 1-2 Torr inside the cluster gun (CG). A dc power of 80-300 Ws was applied to the FePt 50:50 alloy target. Samples were sputtered on $500 \mu \mathrm{m}$ thick Si (100) wafers for magnetic measurements and on Au grids for transmission electron microscopy (TEM) studies. The samples were coated with carbon using a dc power of 24 Ws. Ball milling experiments were performed in a Zirconia milling vial with Zirconia balls using a planetary ball mill (Frithsch Pulverisette 


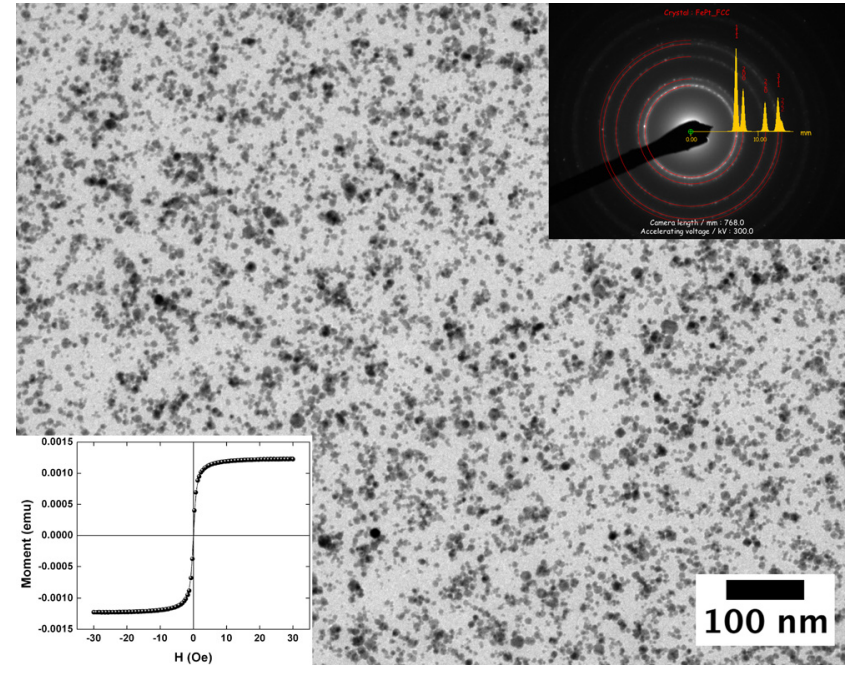

FIG. 1. (Color online) TEM image of the as-made FePt nanoparticles deposited at $80 \mathrm{~W}$ target power; inset shows the SAED and hysteresis loop of the particles.

7). Hexane (99.8\%) was used as the milling medium and oleic acid (OA) (90\%) as the surfactant. Microstructure characterization and composition analyses of the samples were performed with JEOL JEM-3010 TEM and JSM 6330 F SEM. Magnetic measurements at room temperature and below were made with a Quantum Design Versalab vibrating sample magnetometer (VSM) with a maximum field of $3 \mathrm{~T}$. X-ray diffraction (XRD) measurements were made with Rigaku Ultima IV.

\section{RESULTS AND DISCUSSIONS}

Figure 1 shows the as-made nanoparticles at $80 \mathrm{~W}$ target power without the use of the iron pole piece. Particles have the fcc structure (Fig. 1 inset) and soft magnetic properties (Fig. 1 inset). After the introduction of the iron pole piece at the same power, particles started to grow in cubic shape (Fig. 2). However, the surface of the particles is still covered with small clusters that suggest that formation has not ended. In addition to the cubic shape, ordering to $\mathrm{L}_{0}$ has also started (Fig. 2 selected area electron diffraction (SAED) and hysteresis loop insets). These results are similar to the work of Qui et al. ${ }^{11,12}$

At $300 \mathrm{~W}$ target power, samples have been collected both on the Si substrate and near the cluster gun. In the sample collected on $\mathrm{Si}$ substrate $95 \%$ of the particles develop a cubic shape with well defined edges free of small cluster impurities (Fig. 3(a)). Particles have an ultra narrow size distribution with an average particle size of $6.5 \mathrm{~nm}$ and a deviation of $0.2 \mathrm{~nm}$. High resolution TEM (HRTEM) image shows single

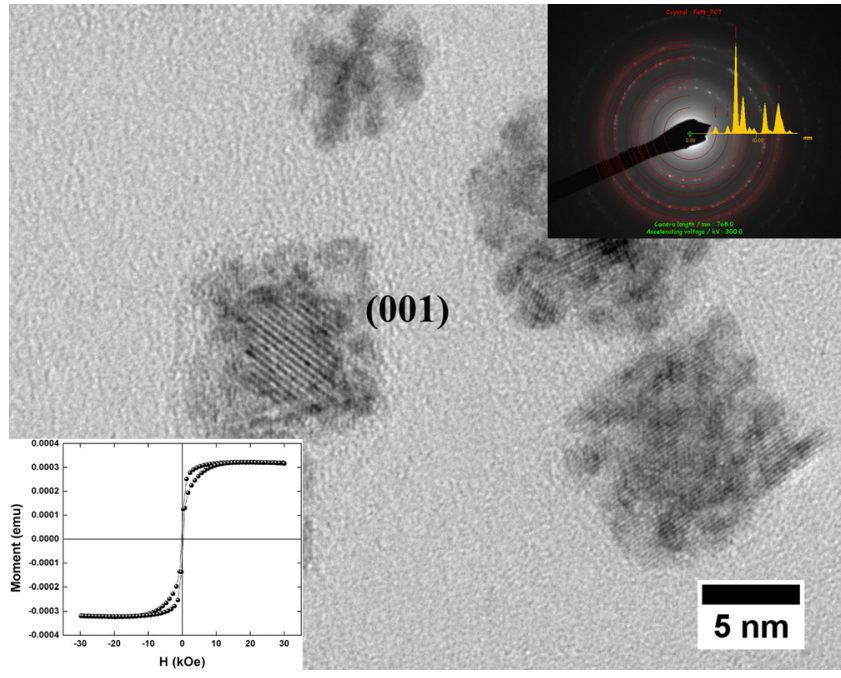

FIG. 2. (Color online) HRTEM image of the as-made FePt nanoparticles deposited at $80 \mathrm{~W}$ target power with iron-pole piece; inset shows the SAED and hysteresis loop of the particles.

crystalline particles indexed to (002) plane of the $\mathrm{L}_{0} \mathrm{FePt}$ (Fig. 3, inset). Further annealing at $600{ }^{\circ} \mathrm{C}$ for $30 \mathrm{~min}$. increased the average particle size to $20 \mathrm{~nm}$. Shape is no longer cubic due to uncontrolled agglomeration (Fig. 3(b)).

Samples near the cluster gun showed a quite different morphology. To our surprise, the samples consisted of FePt micron size rods (Fig. 4(a)). Higher magnification of the rods revealed that the rods consist of $20 \mathrm{~nm}$ size particles (Fig. 4(b)). Possible reason for the rod formation could be the strong magnetic field near the cluster gun. While the $6.5 \mathrm{~nm}$ cubes fly to the Si substrate un-effected, the $20 \mathrm{~nm}$ size particles were strongly magnetic and attracted by the magnetic field, therefore landing near the gun. Due to the outwards radial distribution of the field lines around the gun, the particles formed a rod shape sample. In order to separate these particles from the rod, surfactant assisted ball milling (SABM) technique has been applied to the rods. Particles with size in the range of $10-20 \mathrm{~nm}$ were successfully separated and dispersed on a TEM grid (Fig. 4(c)).

Room temperature hysteresis loops of the as-made $\left(\mathrm{H}_{\mathrm{c}}=2\right.$ $\mathrm{kOe})$ and annealed nanocubes $\left(\mathrm{H}_{\mathrm{c}}=10.2 \mathrm{kOe}\right)$, as-made rods from gun $\left(\mathrm{H}_{\mathrm{c}}=9 \mathrm{kOe}\right)$ and the $\mathrm{SABM}$ separated nanoparticles $\left(\mathrm{H}_{\mathrm{c}}=8 \mathrm{kOe}\right)$ can be seen in Fig. 5. The apparent high switching field of more than $15 \mathrm{kOe}$ observed in the as-made nanocubes may be related to highly ordered particles; this indicates compositional differences among the particles, even though the average composition of the particles from the energy-dispersive X-ray

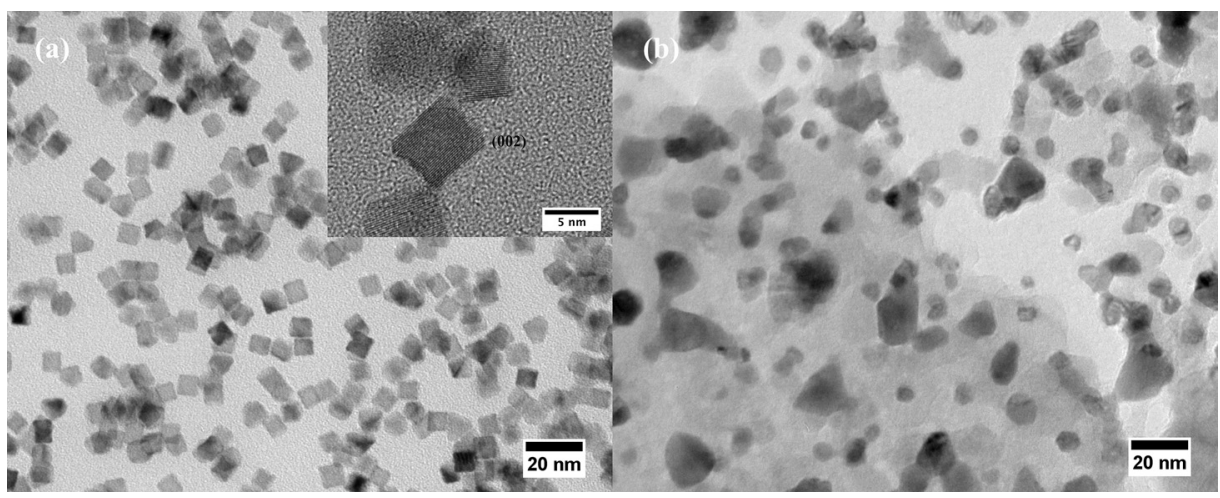

FIG. 3. (a) TEM image of the as-made FePt nanoparticles deposited at $300 \mathrm{~W}$ target power with iron-pole piece; inset shows the HRTEM of the particles, (b) After annealing at $600{ }^{\circ} \mathrm{C}$ for $30 \mathrm{~min}$. 


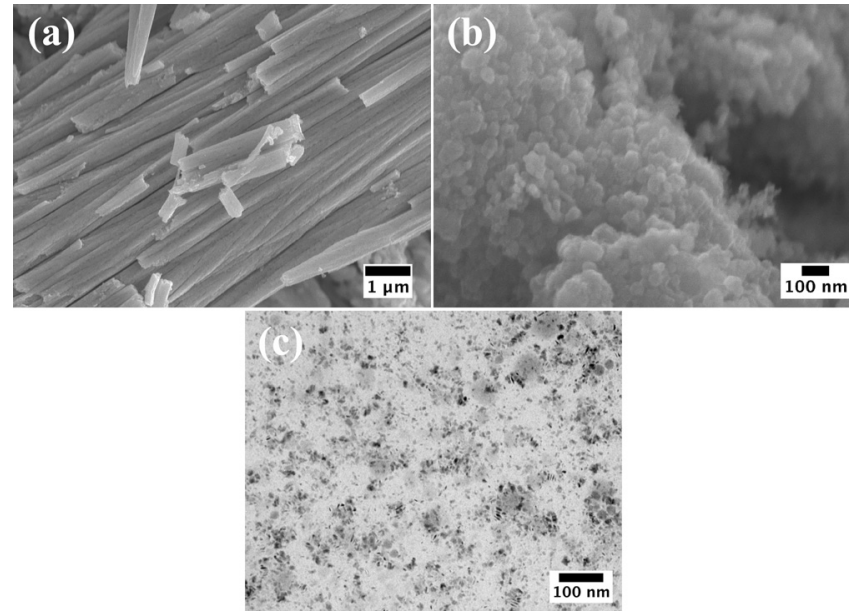

FIG. 4. (a) SEM image of the as-made FePt rods collected from near the cluster gun deposited at $300 \mathrm{~W}$ target power with iron-pole piece, (b) higher magnification SEM image of the rods, (c) TEM image of the FePt particles from the rods after SABM.

spectroscopy analysis is close to $50: 50 .^{15}$ On the other hand, a possible reason for the average low coercivity could be due to Pt segregation on the surface of the FePt nanoparticles, which creates a soft or non-magnetic layer on the surface. ${ }^{16}$ This is not the case for the rods since they spent more time near the cluster gun and became more ordered.

XRD data for the as-made and annealed nanocubes and as-made rods can be seen in Fig. 6. Ordering parameter $S\left(\left(I_{S} I_{f 0} / I_{S 0} I_{f}\right)^{1 / 2}\right)^{17}$ for all three samples has been calculated. Order parameters $\mathrm{S}$ are found $0.5,1$, and 0.85 for the as-made, annealed nanocubes and as-made rods, respectively. $\mathrm{SiO}_{2}$ contamination of the rod sample is due to sand blaster that has been used to collect samples from the vicinity of the gun.

Previous reports showed that the typical single crystal FCT FePt nanoparticle shape is octahedral because it has the lowest energy. ${ }^{11,12}$ Although particles with the low ordering parameter 0.5 have the cubic shape, the possibility of particles becoming octahedral by improving the ordering cannot be excluded. On the other hand, at very high sputtering power it is very unlikely to expect the typical shape formations due to the non-equilibrium conditions.

Morphology and structure analysis is underway for FePt nanoparticles deposited at even higher powers and higher pressures.

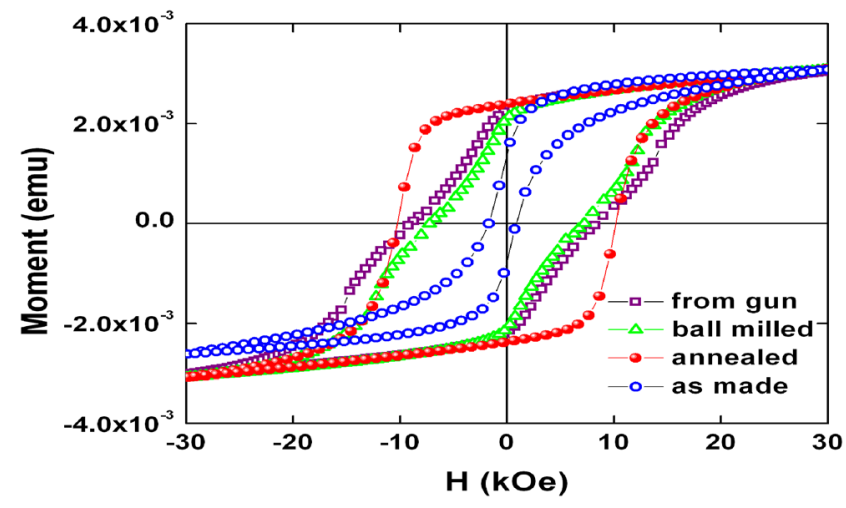

FIG. 5. (Color online) Hysteresis loops of the as-made and annealed nanocubes, as- made rods from gun and the SABM separated nanoparticles at room temperature.

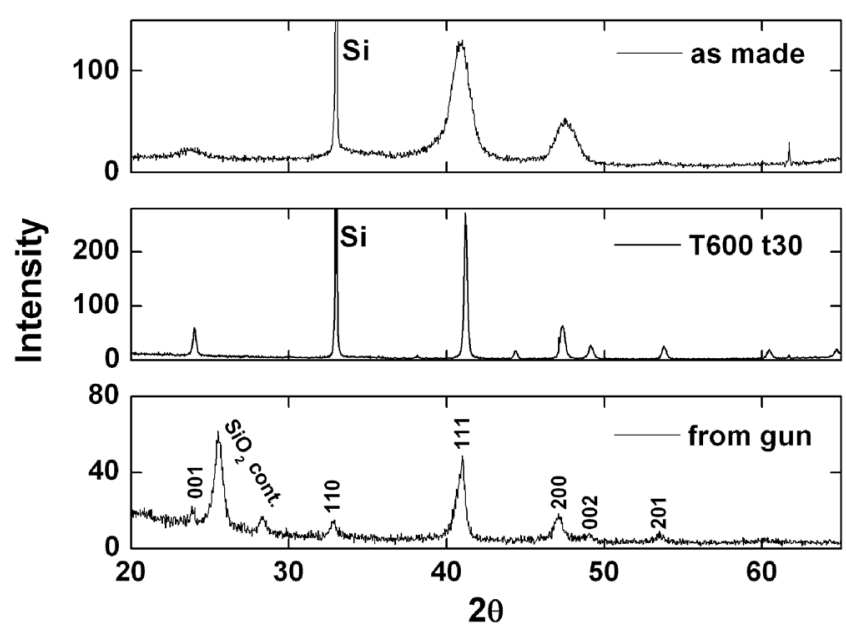

FIG. 6. XRD data of the as-made and annealed nanocubes and as-made rods from gun.

\section{CONCLUSIONS}

Ordered FePt nanocubes with an average size of $6.5 \mathrm{~nm}$ have been produced with one step fabrication using the $\mathrm{Fe}$ pole piece attached to the cluster gun at very high target powers $(300 \mathrm{~W})$. In addition to the nanocubes, rod formation has been observed near the cluster gun. These rods are highly ordered and consist of $20 \mathrm{~nm}$ average size nanoparticles. The nanoparticles were separated by SABM technique by using the oleic acid as the surfactant and Hexane as the milling media. Both the nanocubes and the nanoparticles (separated from the rods) are potential candidates for the next generation ultra high density magnetic recording media.

\section{ACKNOWLEDGMENTS}

The authors would like to thank A. M. Gabay for helpful discussions. Work was supported by DOE DE-FG02-04ER4612.

${ }^{1}$ M. E. McHenry and D. E. Laughlin, Acta Mater. 48, 223 (2000).

${ }^{2}$ G. C. Hadjipanayis, J. Magn. Magn. Mater. 200, 373 (1999).

${ }^{3}$ L. X. Tiefenauer, A. Tschirky, G. Kühne, and R. Y. Andres, Magn. Reson. Imaging 14, 391(1996).

${ }^{4}$ O. Gutfleisch, M. A. Willard, E. Brück, C. H. Chen, S. G. Sankar, and J. P. Liu, Adv. Mater. 23, 821 (2011).

${ }^{5}$ N. A. Frey and S. Sun, Magnetic Nanoparticle for Information Storage Applications Inorganic Materials (CRC, Boca Raton, 2010), pp. 33-68.

${ }^{6}$ S. Sun, C. B. Murray, D. Weller, L. Folks, and A. Moser, Science 287, 1989 (2000)

${ }^{7}$ O. Gutfleisch, J. Lyubina, K. H. Müller, and L. Schultz, Adv. Eng. Mater. 7, 208 (2005).

${ }^{8}$ V. Tzitzios, G. Basina, L. Colak, D. Niarchos, and G. C. Hadjipanayis, J. Appl. Phys. 109, 07A718 (2011).

${ }^{9}$ S. Stoyanov, Y. Huang, Y. Zhang, V. Skumryev, G. C. Hadjipanayis, and D. Weller, J. Appl. Phys. 93, 7190 (2003).

${ }^{10} \mathrm{~S}$. Stappert, B. Rellinghaus, M. Acet, and E. F. Wassermann, J. Cryst. Growth 252, 440 (2003).

${ }^{11}$ J. M. Qiu and J. P. Wang, Appl. Phys. Lett. 88, 192505 (2006).

${ }^{12}$ J. M. Qiu, J. Bai, and J. P. Wang, Appl. Phys. Lett. 89, 222506 (2006).

${ }^{13}$ X. Liu, S. He, J. M. Qiu, and J. P. Wang, Appl. Phys. Lett. 98, 222507 (2011).

${ }^{14}$ O. Akdogan, W. Li, G. C. Hadjipanayis, and D. J. Sellmyer, J. Nanopart. Res. 13, 7005 (2011).

${ }^{15}$ H. B. Wang, H. Wang, J. Zhang, F. J. Yang, Y. M. Xu, and Q. Li, Nanoscale Res. Lett. 5, 489 (2010).

${ }^{16}$ R. M. Wang, O. Dmitrieva, M. Farle, G. Dumpich, H. Q. Ye, H. Poppa, R. Kilaas, and C. Kisielowski, Phys. Rev. Lett. 100, 017205 (2008).

${ }^{17}$ M. Tanase, J. G. Zhu, C. Liu, N. Shukla, T.J. Klemmer, D. Weller, and D.E. Laughlin, Metall. Mater. Trans. 38A, 798 (2007). 